\title{
Calcium: Too Much of a Good Thing?
}

\author{
Denise Millstine, MD, Larry Bergstrom, MD, ${ }^{2}$ and Anita P. Mayer, $\mathrm{MD}^{1}$
}

\section{Case Report}

A 60-YEAR-OLD Caucasian female with a history of hypertension, anxiety, depression, and osteopenia presents for her periodic health examination. Current medications include metoprolol, venlafaxine, and a multivitamin (contains $220 \mathrm{mg}$ calcium). She takes calcium citrate with vitamin D (2 tablets $=500 \mathrm{mg}$ elemental calcium and $800 \mathrm{IU}$ vitamin D), 6 tablets daily. Her total daily dose of elemental calcium is $1500 \mathrm{mg}$. She has no personal or family history of previous fracture. She does not smoke tobacco or use alcohol. Her diet includes about 1 serving of yogurt or cheese daily. Her dualenergy x-ray absorptiometry (DEXA) performed 2 years ago showed a lumbar spine T-score of -2.3 and right femoral neck T-score of -2.4 . Physical exam reveals a body mass index (BMI) of 28.7 and is otherwise normal. A recent $25-\mathrm{OH}$ vitamin D level was $32 \mathrm{ng} / \mathrm{mL}$. Her FRAX score calculation estimates her 10 -year risks at $14 \%$ for major osteoporotic fracture and $1.6 \%$ for hip fracture. The best recommendation for calcium intake regarding prevention of osteoporotic fracture is:

A. Continue current dietary and supplemental calcium intake.

B. Decrease dietary calcium intake.

C. Increase dietary calcium intake to 2 servings of yogurt or cheese per day.

D. Discontinue supplemental calcium.

E. Recommend dietary calcium goal of $1000-1200 \mathrm{mg}$.

\section{Discussion}

Vitamin D and calcium supplementation have long been considered important in the prevention of osteoporosis and osteoporotic fractures. In 2011, the Institute of Medicine (IOM) concluded that calcium homeostasis, in which vitamin $\mathrm{D}$ has a key role, is essential for bone health. For women over 50 , the IOM's recommended daily allowance (RDA) for calcium is $1200 \mathrm{mg}$. The IOM also recommends daily vitamin D $600 \mathrm{IU}$ for adult women less than 70 years old and $800 \mathrm{IU}$ for those older. ${ }^{1}$

In 2013, however, the United States Preventive Services Task Force (USPSTF) changed their recommendations regarding calcium and vitamin D supplements for bone health. The USPSTF now states that supplementation with 400 IU or less of vitamin D and $1000 \mathrm{mg}$ or less of calcium has no effect on preventing fractures in postmenopausal, community dwelling women without prior diagnosis of osteoporosis. ${ }^{2}$ The group further finds the benefits and harms of higher doses of these supplements as uncertain. In response, some experts have gone so far as to say, "do not supplement" healthy, postmenopausal women. ${ }^{3}$

The efficacy of calcium supplements for fracture prevention is far from clear. Recent reviews of the literature have demonstrated that calcium improves bone density but does not provide protection from fractures. ${ }^{4,5,6}$ One review did find small improvements in fracture risk, but only with subgroup analyses. ${ }^{7}$ A large meta-analysis in 2007 demonstrated a reduced rate of bone loss and a $12 \%$ reduction in fractures, in adults 50 and over who were taking calcium supplementation. $^{8}$ Still another meta-analysis showed no relationship between calcium supplementation on bone density or fracture risk. ${ }^{9}$

Calcium's role in osteoporosis is complicated by its association with vitamin D. Calcium supplements are commonly paired with vitamin $\mathrm{D}$ and studies often assess the efficacy of the two together. Vitamin D has been controversial, but a recent meta-analysis has shown reduction in both hip fracture and nonvertebral fracture in people ingesting 700-2000 IU daily. ${ }^{10}$ The vitamin D requirement among individual patients can be variable, especially in those at increased risk for osteoporotic fracture. This patient has an adequate serum $25-\mathrm{OH}$ vitamin $\mathrm{D}$ level $>30 \mathrm{ng} / \mathrm{mL}$. The current vitamin D supplement dosing is well below the safe upper limit of $4000 \mathrm{IU} /$ day $^{11}$ and should be continued.

The issue of calcium supplementation requires careful consideration as nearly two-thirds of American women over 50 take calcium in supplement form. ${ }^{12}$ Calcium supplementation has traditionally been encouraged, as only $30 \%$ of the U.S. population ingests adequate calcium in their diet. ${ }^{13}$ The issue is further complicated by the $39 \%$ of women who are exceeding the RDA when combined dietary and supplemental calcium are considered. ${ }^{12}$

Whether calcium supplements are entirely safe is another consideration. High doses have been associated with nephrolithiasis. ${ }^{2,14}$ Less clear, and more potentially harmful, is the relationship between calcium supplements and cardiovascular events. The 2010 meta-analysis by Bolland et al.

Divisions of ${ }^{1}$ Women's Health - Internal Medicine and ${ }^{2}$ Consultative Medicine, Mayo Clinic in Arizona, Phoenix, Arizona. 
demonstrated a $30 \%$ increase in myocardial infarction (MI) among those assigned to taking calcium supplements. Further, the amount of calcium intake mattered. An increased risk of MI was only seen in people with dietary intakes of calcium above the median of $805 \mathrm{mg}$ per day. ${ }^{15}$ Analysis of the Women's Health Initiative Calcium and Vitamin D Study (WHI CaD) data has been inconsistent. A recent reanalysis did show a modest increase in risk of myocardial infarction among women assigned to calcium supplementation. ${ }^{16}$ Initial analysis of the same data had not shown an increase in MI or cardiovascular death. ${ }^{17}$ Another analysis showed no difference in overall mortality. ${ }^{18}$

Dietary intake of calcium is probably not cardiotoxic. Dietary calcium without additional supplementation was associated with a protective effect from ischemic heart disease decades ago. ${ }^{15,19}$ A more recent, large, prospective European study demonstrated protection from MI in higher dietary calcium intake, but a significantly increased risk of MI (hazard risk $[H R]=1.86)$ in patients taking calcium supplements. ${ }^{20}$ Furthermore, calcium supplement users with high dietary calcium intake ( $1400 \mathrm{mg} /$ day) more than doubled their risk of mortality $(\mathrm{HR}=2.57)$ in a Swedish cohort. ${ }^{21}$ In the large AARP study, calcium supplement use was associated with increased cardiovascular death in men but not in women. Dietary calcium intake did not affect death rate. ${ }^{22}$

While this evidence is far from definitive, it does suggest the importance of careful quantification of dietary and supplemental calcium use among women with preference for dietary calcium intake.

\section{Answer:The Correct Answer Is E}

This patient is taking excessive calcium between her diet and supplement, totaling $1720 \mathrm{mg}$ daily, or $168 \%$ of the RDA. She should not continue this current intake.

Calcium from food sources has not been linked to morbidity, so limiting dietary consumption would not be advised. In order to help patients estimate their average daily dietary intake, consider that a single serving of yogurt contains about $350 \mathrm{mg}$ of elemental calcium and a serving of cheese has about $250 \mathrm{mg}$.

Increasing her intake to two servings of yogurt or cheese daily without addressing her current calcium supplementation would further increase her excessive intake. Similarly, a recommendation to simply discontinuing her supplements would be inadequate.

In order to avoid the potential toxicity of high dose calcium supplements, answer $\mathrm{E}$ is correct. The recommendation should be to decrease her total daily intake to $1000-1200 \mathrm{mg}$, optimally from dietary sources.

\section{Disclosure Statement}

No competing financial interests exist.

\section{References}

1. Institute of Medicine (IOM). Dietary reference intakes for calcium and vitamin D. Washington, DC: The National Academies Press, 2011.

2. Moyer VA. Vitamin D and calcium supplementation to prevent fractures in adults: U.S. preventive services task force recommendation statement. Ann Intern Med 2013; 158:691-696.

3. Nestle M, Nesheim MC. To supplement or not to supplement: The U.S. Preventive Services Task Force recommendations on calcium and vitamin D. Ann Intern Med 2013; 158:701-702.

4. Reid IR, Bolland MJ, Grey A. Effect of calcium supplementation on hip fractures. Osteoporos Int. 2008;19:11191123.

5. Seeman E. Evidence that calcium supplements reduce fracture risk is lacking. Clin J Am Soc Nephrol 2010;5: S3-11.

6. Jackson RD, LaCroix AZ, Gass M, et al. Calcium plus vitamin $\mathrm{D}$ supplementation and the risk of fractures. $\mathrm{N}$ Engl J Med 2006;354:669-683.

7. Bischoff-Ferrari HA, Dawson-Hughes B, Baron JA, et al. Calcium intake and hip fracture risk in men and women: A meta-analysis of prospective cohort studies and randomized controlled trials. Am J Clin Nutr 2007;86: 1780-1790.

8. Tang BM, Eslick GD, Nowson C, Smith C, Bensoussan A. Use of calcium or calcium in combination with vitamin $\mathrm{D}$ supplementation to prevent fractures and bone loss in people aged 50 years and older: a meta-analysis. Lancet 2007; 370:657-666.

9. Rabenda V, Bruyere O, Reginster JY. Relationship between bone mineral density changes and risk of fractures among patients receiving calcium with or without vitamin D supplementation: A meta-regression. Osteoporos Int 2011;22: 893-901.

10. Bischoff-Ferrari HA, Willett WC, Orav EJ, et al. A pooled analysis of vitamin D dose requirements for fracture prevention. N Engl J Med 2012;367:40-49.

11. National Osteoporosis Foundation (NOF). Clinician's guide to prevention and treatment of osteoporosis. Washington, DC: National Osteoporosis Foundation, 2013.

12. Bailey RL, Dodd KW, Goldman JA, et al. Estimation of total usual calcium and vitamin D intakes in the United States. J Nutr 2010;140:817-822.

13. Nicklas TA, O'Neil CE, Fulgoni VL, 3rd. The role of dairy in meeting the recommendations for shortfall nutrients in the American diet. J Am Coll Nutr 2009;28:73S-81S.

14. Wallace RB, Wactawski-Wende J, O'Sullivan MJ, et al. Urinary tract stone occurrence in the Women's Health Initiative (WHI) randomized clinical trial of calcium and vitamin D supplements. Am J Clin Nutr 2011;94: 270-277.

15. Bolland MJ, Avenell A, Baron JA, et al. Effect of calcium supplements on risk of myocardial infarction and cardiovascular events: Meta-analysis. BMJ 2010;341:c3691.

16. Bolland MJ, Grey A, Avenell A, Gamble GD, Reid IR. Calcium supplements with or without vitamin D and risk of cardiovascular events: reanalysis of the Women's Health Initiative limited access dataset and meta-analysis. BMJ 2011;342:d2040.

17. Hsia J, Heiss G, Ren H, et al. Calcium/vitamin D supplementation and cardiovascular events. Circulation 2007;115: 846-854.

18. LaCroix AZ, Kotchen J, Anderson G, et al. Calcium plus vitamin D supplementation and mortality in postmenopausal women: the Women's Health Initiative calcium-vitamin D randomized controlled trial. J Gerontol A Biol Sci Med Sci 2009;64:559-567. 
19. Knox EG: Ischaemic-heart-disease mortality and dietary intake of calcium. Lancet 1973;1:1465-1467.

20. Li K, Kaaks R, Linseisen J, Rohrmann S. Associations of dietary calcium intake and calcium supplementation with myocardial infarction and stroke risk and overall cardiovascular mortality in the Heidelberg cohort of the European Prospective Investigation into Cancer and Nutrition study (EPIC-Heidelberg). Heart. 2012;98:920-925.

21. Michaelsson K, Melhus H, Warensjo Lemming E, Wolk A, Byberg L: Long term calcium intake and rates of all cause and cardiovascular mortality: Community based prospective longitudinal cohort study. BMJ 2013;346:f228.

22. Xiao Q, Murphy RA, Houston DK, Harris TB, Chow WH, Park Y. Dietary and supplemental calcium intake and car- diovascular disease mortality: the National Institutes of Health-AARP diet and health study. JAMA Intern Med 2013; 173:639-646.

Address correspondence to: Denise Millstine, $M D$

Division of Women's Health - Internal Medicine

Mayo Clinic in Arizona 13737 N. 92nd Street Scottsdale, AZ 85260

E-mail: millstine.denise@mayo.edu 